\title{
Cubiu [Solanum topiro (Humb. \& Bonpl.)], uma fruteira da Amazônia
}

\author{
Alejo von der Pahlen (")
}

\begin{abstract}
Resumo
É descrita a coleção, comportamento agronômico e a variabilidade genética do cubiu (Solanum topiro $\mathrm{H}$ \& B), uma frutifera herbácea. Foram coletadas 35 introduçōes na Amazônia, desde Belém do Pará (Brasil) até Iquitos (Peru). Uma grande variabiliclade genética foi encontrada para forma e tamanho do fruto, especialmente na região oeste. Parte da coleção foi plantada. A produção começou aos 6-7 meses após a semeadura e praticamente terminou 3 meses depois. A produção de frutos, por planta, variou de $2,5 \mathrm{~kg}$ até 14 $\mathrm{kg}$ dependendo do solo e do genótipo.
\end{abstract}

\section{INTRODUÇÃO}

O cubiu é uma planta frutífera herbácea amazonense, cujo potencial para sua industrialização e consumo direto, ainda não foi devida. mente estudado no Brasil.

Poucas pesquisas foram feitas com esta espécie e as revisões de fruteiras tropicais só a citam de forma acidental e limitan'do-a, em geral, a uma área restrita (Kennard \& Winters, 1960), (Brücher, 1973), quando ha realidade cresce em toda a Amazônia.

Em comparação com a maior parte das espécies frutíferas, ela apresenta a vantagem de ter um ciclo curto que permite um investimento menor, embora sua produção também tenha ciclo curto. Na procura de alternativas para a agricultura da Amazônia, c Setor de Hortaliças do INPA reuniu uma coleção e realizou testes de produtividade de diversas origens, algumas das quais estãc em andamento. Os experimentos preliminares sugerem que seu cultivo pode ser rentável.

\section{Consumo}

Os frutos dessa solanácea herbácea, não tuberosa, são utilizados para sucos, doces, geléias, compotas, cozido com peixe e misturado em saladas. Substitui com vantagem a maçă nas tortas, por ser mais azeda. Sugestivamente, em inglês é denominada como "Orinoco
Apple". Na Amazônia brasileira e colombiana. aproveita-se em escala doméstica e, na Amazônia peruana, onde é conhecida como cocona, é industrializada. Adicionando-se 8 a $10 \%$ de açúcar obtemos um refrigerante, ou batida semelhante à caipirinha, muito agradável. Devido ao seu alto conteúdo em ácido cítrico, o suco do cubiu pode substituir o limão.

Os indios do alto Orinoco, onde é conhecido como tupiro ou topiro, o usam mas não o cultivam (Brücher, 1973).

\section{ORIGEM E DISTRIBUIÇÃO}

De acordo com Brücher (1973), a origem é no Alto Orinoco. Planta-se em toda a Amazônia, no Brasil, Peru, Colômbia (Patiño, 1962) e, aparentemente, na Venezuela e no trópico úmıdo baixo. É comum no Estado do Amazonas, onde se pode encontrar como subespontânea É mais rara no Estado do Pará. Habitualmente é mantida no quintal familiar; aparece regularmente nos mercados do oeste do Amazonas, no Brasil, Colômbia e Peru e, ocasionalmente, em Belém do Pará. Com o objetivo de avaliar as possibilidades de cultura do cubiu, foi feita uma coleção aproveitando as viagens do pessoal da Divisāo de Ciências Agronômicas do INPA. $\mathrm{Na}$ Tabela 1, figura a quantidade de introduções em cada área da Amazônia.

\section{NÚMERO CROMOSSÔMICO}

Foi observado o número de $2 n=24$, pela primeira vez, por Marti (Brücher, 1968) e confirmado posteriormente por Suely Werninck, do INPA.

\section{ECOLOGIA}

O cubiu é um arbusto que cresce no latossolo e no solo franco arenoso do trópico úmido baixo da Amazônia. Reage muito bem a adição de matéria orgânica ou uréia. É uma planta heliófila; na sombra cresce menos que em pleno sol.

(•) - Instituto Nacional de Pesquisas da Amazônia, Manaus. 
TABEL 1

Número de introduções do cubiu, de diversas localidades da Amazônia

\begin{tabular}{|c|c|c|c|c|c|c|c|c|c|c|c|}
\hline LOCAL & Belém & Manous & $\begin{array}{l}\text { Ilhas } \\
\text { Anavi- } \\
\text { Ihanas }\end{array}$ & Lóbrea & $\begin{array}{l}\text { Tama- } \\
\text { nicuo }\end{array}$ & $\begin{array}{l}\text { Benjamin } \\
\text { Constont }\end{array}$ & $\begin{array}{l}\text { Atalia do } \\
\text { Norte }\end{array}$ & $\begin{array}{c}\text { EI } \\
\text { Marco }\end{array}$ & Tefó & $\begin{array}{c}\text { Iquitos } \\
\text { Peru }\end{array}$ & TOTAL \\
\hline N..$^{\circ}$ & 2 & 8 & 2 & 1 & 1 & 2 & 1 & 3 & 7 & 8 & 35 \\
\hline
\end{tabular}

Quando as condições são adversas, o desenvoivimento da planta e o número de frutas é menor, mas o tamanho das folhas e frutos permanecem quase invariáveis, ao contrário do que sucede em outras solanáceas, como o fumo, tomate e pimentão, onde o tamanho de fothas e frutos varia de acordo com as condições de desenvolvimento.

Se as plantas são deixadas em vasos de 1 a 2 litros de capacidade sem efetuar transplante, as mesmas ficam quase que sem crescer durante pelo menos um ano.

Foi constatada a presença de micorrhizas nas raizes de cubiu pelo Dr. Theodore St. John, organismos que aparentemente facilitam a ab sorção de nutrientes especialmente fósforo.

\section{DESCRIÇão BOTÂNICA}

A.rbusto de 1,00 a $2,00 \mathrm{~m}$ de altura, ereto, ramificado, de 1 até três anos de vida em condições boas de desenvolvimento; raízes laterais estendendo-se até $1,40 \mathrm{~m}$ da base da planta. As folhas cobrem uma área pouco menor. Toda a parte aérea é coberta por uma pilosidade densa, sem espinhos (Fig. 1a. e b).

Folhas simples, alternas, com arranjo em empiral (em grupos e três), longa peciolada, ovalada, membranácea, margem lobada-dentada, ápice agudo, dentes com ápice micronado, base assimétrica.

As folhas maiores têm peciolos de até $14 \mathrm{~cm}$ de comprimento e lâminas de até $58 \mathrm{~cm}$ de comprimento. O lado dorsal das lâminas é de cor cinza, a ventral está coberta por uma substância aparentemente açucarada que atra: himenópterōs (apidae, vespidae, formicidae) € dípteros. Folhas novas levemente ferrugino. sas.
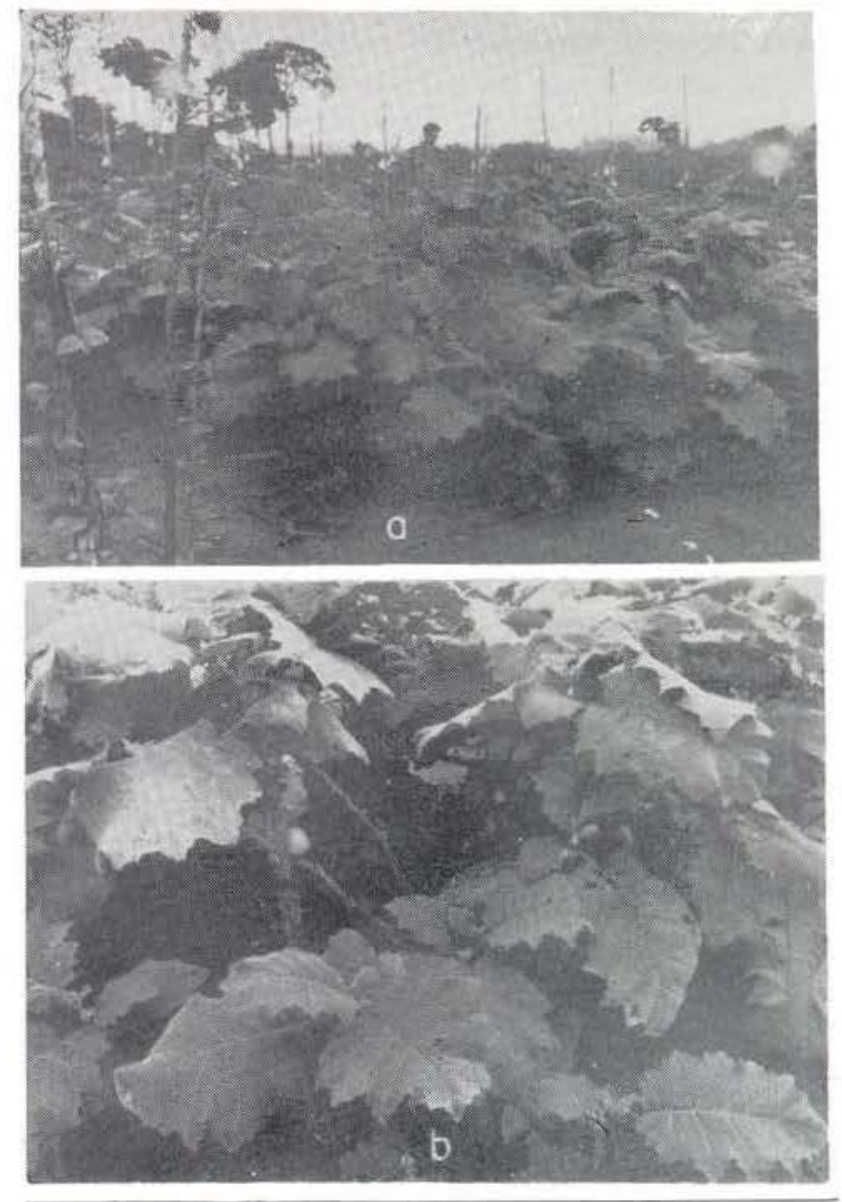

Fig. 1a. e 1b. - Aspectos do plantio de cubiu.

Inflorescências formadas por cinco a oito flores, das quais, ficam uma a três frutas situadas nos ramos entre cada grupo de três folhas.

A inflorescência é uma cima formada por um ramo de pouco mais de um centimetro de comprimento no qual se situam, em forma espiralada, os pendúnculos florais de 2 a $5 \mathrm{~mm}$ de comprimento. Pétalas verde-claras, sépalas 
verdes, cálice maior que a corola, anteras amarelas em número de cinco de $3 \mathrm{~cm}$ de comprimento e $1 \mathrm{~cm}$ de largura.

Fruto de forma variada de acordo com o genótipo, redonda, achatada, quinada ou alon. gada (Fig. 2), verde quando imadura, amarela quando madura e tornando-se finalmente de um marrom avermelhado, cobertos de pêlos curtos quebradiços que são facilmente removidos esfregando-se os frutos. Pele grossa, de gosto amargo, polpa amarela de 1,00 a $2,50 \mathrm{~mm}$ de espessura dependendo do genótipo. A variação genética da forma levou a (Schultes \& RomeroCastañeda, 1962) dar-lhes um nome diferente (S. alibile R. E. Schultes sp. nov.) para a forma globosa o que não é justificado. A mesma causa levou Dunal a dar outro nome ao cubiu do Pará. Solanum Sessiliforum D. De acordo com a descrição de Sendtner (1846) a única diferença consistiria na presença ocasional de espinhos (subinermis) e por ter um cálice maior que a corola (Correa, 1931). Todavia, as introduções de Belém são idênticas as de outras localidades e sua distribuição e hábitos são os mesmos (Ducke, 1946). Portanto, são consideradas como idênticas as duas espécies apresentadas no presente trabalho.

Os frutos oblongos têm quatro lóculos e os frutos redondos de quatro a seis. A variação do número de lóculos nos frutos redondos ocorre dentro da mesma planta. Cada fruto contém de 500 a 2000 sementes glabras, ovaladas, achatadas. O peso de mil sementes é de $1,20 \mathrm{~g}$, e o dos frutos varia entre 30 a $400 \mathrm{~g}$, dependendo do genótipo. Para um mesmo genótipo é quase invariável, $\in \mathrm{m}$ diferentes condições ambientais, como já foi mencionado. De acorcio com Schultes \& Romero-Castañeda (1962) existe outra espécie Solanum platyphyl. lum Humb. e Bonpl. no oeste da Amazônia com frutos menores que $2 \mathrm{~cm}$ de diâmetro.

\section{Polinizaçìo}

É uma planta autofecundada, como se pode inferir do fato que as plantas isoladas apresen. tam uma boa produção, mas deve ter uma certa quantidade de cruzamentos naturais, porque sempre foi observada a presença de abelhas sociais e solitárias visitando flores e carregando pólem.

\section{COMPOSIÇÃo QUÍMICA}

No Simpósio sobre Alimentos da Amazônia em 1963, organizado pelo Ministério da Saúde, Comissão Nacional de Alimentação, Belém, a composição química dada para o cubiu do Pará Solenum sessilifiorum, é a seguinte:

TABELA 2

Composição química do cubiu

\begin{tabular}{|c|c|c|c|c|c|c|}
\hline$\%$ Unidade & $\begin{array}{l}\text { Extr. \% } \\
\text { etereo }\end{array}$ & $\begin{array}{l}\text { Proteína } \\
\text { bruta \% }\end{array}$ & $\begin{array}{c}\text { Fibra } \\
\text { bruta } \%\end{array}$ & $\begin{array}{l}\text { Carboi- } \\
\text { drato } \%\end{array}$ & $\begin{array}{l}\text { Cálcio } \\
\text { mg \% }\end{array}$ & $\mathrm{mg}^{\mathbf{P}} \%$ \\
\hline$\% 92$ & 1,4 & 0,6 & 0,4 & 5,7 & 12 & 14 \\
\hline
\end{tabular}

\begin{tabular}{c|c|c|c|c}
\hline $\begin{array}{c}\mathrm{Fe} \\
\mathrm{mg} \%\end{array}$ & $\begin{array}{c}\text { Caroteno } \\
\mu \mathrm{g} \%\end{array}$ & $\begin{array}{c}\text { Tiamina } \\
\mu \mathrm{g} \%\end{array}$ & $\begin{array}{c}\text { Ribofla- } \\
\text { vina } \mu \mathbf{g} \%\end{array}$ & $\begin{array}{c}\text { Niacina } \\
\mu \mathrm{g} \%\end{array}$ \\
\hline 0,6 & 140 & 25 & - & 500 \\
\hline
\end{tabular}




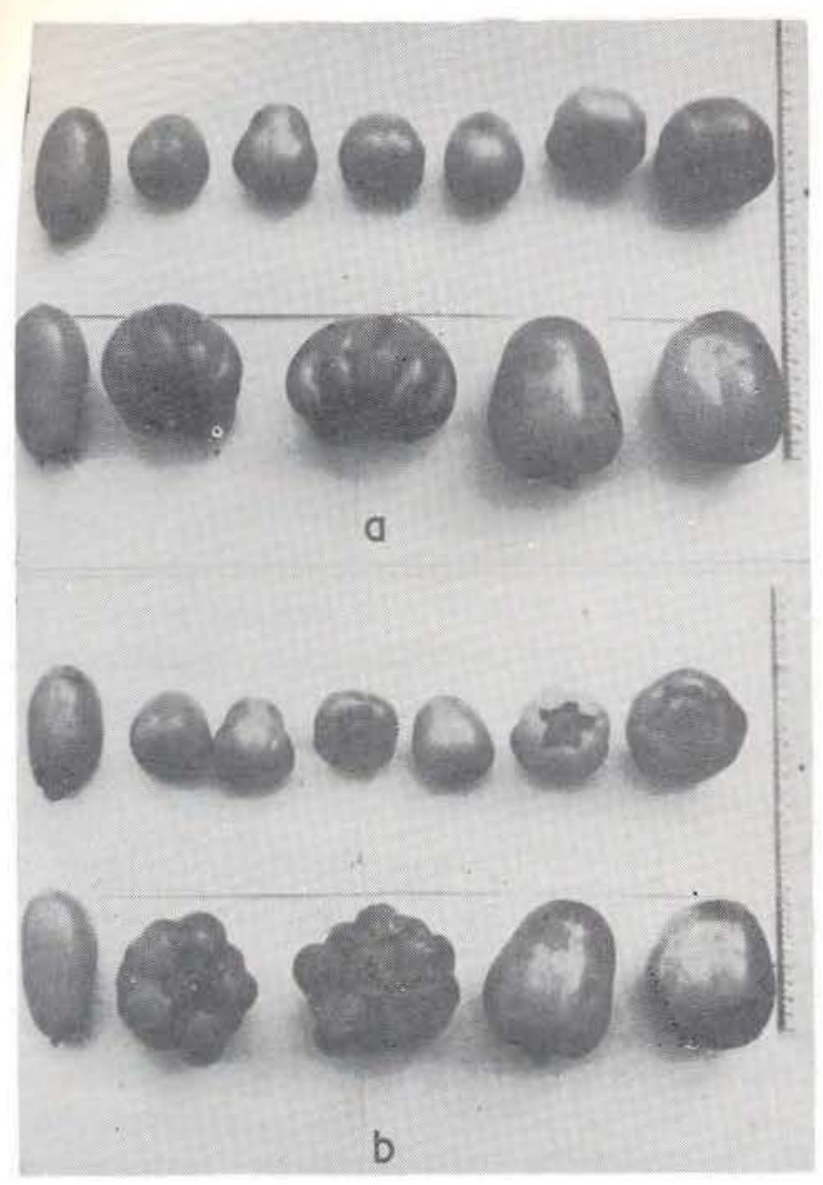

Fig. $2 a$ e $2 b-$ Variação da forma do fruxo de cubiu.

A análise feita por Czyrinciw e Herrera no Departamento de Tecnologia e Alimentos, Universidade de Caracas (Brücher, 1968) em Solanum topiro, dá um conteúdo de taninos de $142 \mathrm{mg}$ em $100 \mathrm{~g}$, de vitamına C de $5,3 \mathrm{mg}$ em $100 \mathrm{~g}$, proteina $0,5 \%$ e acidez $1,8 \%$. Não se detectou tóxicos, nem alcalóides. O Professor Ayssor Mourão (Comunicação pessoal), obteve um conteúdo de ácido cítrico de $0,8 \%$.

Nas introduções do INPA foi feita a medicia do indice refratométrico, obtendo-se 4 a 5 graus Brix, dado que é semelhante ao publicado para o conteúdo de carboidratos pelo Ministério da Saúde.

\section{Propagação E CULTURA}

É propägado por sementes em canteiro de semeadura da mesma maneira que o tomateiro, pimentão ou berinjela, todavia tem um desen- volvimento mais lento e é mais sensivel ao transplante. Por essa razão, foi mais conveniente repicá-lo para saco de plástico três a quatro semanas depois da semeadura e trans. plantá-lo para o lugar definitivo, um mês e meio ou dois, mais tarde.

Nos plantios do INPA, o espaçamento entre os mesmos é de $1 \times 1 \mathrm{~m}$, que se verificou mais tarde ser demasiado pequeno, passancio-se a plantar com espaços de $1,30 \times 1,30 \mathrm{~m}$. Não são conhecidos ainda os dados desse espaçamento. $\mathrm{O}$ cubiu pode crescer sem nenhum adubo, mas nesse caso a produção é baixa sendo de aproximadamente, $2,9 \mathrm{~kg}$ por planta (20-30 frutos), o que representa um rendimento de 29 ton/ha. Só ádubando com lixo orgânico (250 ton/ha) e uma fertiiização em cobertura no início daa produção com $10 \mathrm{~g}$ de superfosfato triplo, $10 \mathrm{~g}$ de uréia e $10 \mathrm{~g}$ de cloreto de potassio em solo arc noso com 80 a $85 \%$ de areia, obteve-se em três meses de produção um rendimento (que variou cie acordo com a origem) entre $14 \mathrm{~kg}$ por planta (136 trutos, 146 ton/ha) nas linhagens mais produtivas, e $5,0 \mathrm{~kg}$ por planta $(40-50$ frutos, 25 ton/ha) nas linhagens menos produtivas. A média das produções das introduções nesse sclo foi de 56 ton/ha. Brücher (1968), cita para Venezuela, uma produção de 20 a 40 frutos por planta.

Nessa experiência o solo ficou com um maior conteúdo de matéria orgânica que pode. rá seí aproveitada posteriormente por culturas resistentes, ou tolerantes aos nematóides.

A floração começa aos dois ou trés meses depois que foi feito o transplante, acima do segundo e terceirc grupo de folhas. As frutas amadurecem oito semanas após a polinização. A produção começa quatro a cinco meses depois que o transpiante foi realizado, ou seja, aproximadamente após sete meses de semeadura.

\section{PRAgas E DOENÇAS}

A única praga detectada, por enquanto, foi um hemíptero da família dos Tingidae, que se iocaliza na parte inferior das folhas. Aquelas ficam com uma cor marrom-queimado e os espaços internervais caem. As pulverizaçōes com inseticidas fosforados, podem controlar o inseto. 
De acordo com informaçōes do Instituto Adventista Agrícola Industrial, onde a murcha bacteriana é endêmica, o cubiu tem se desenvolvido bem em solos infectados, o que faz supor que ele é resistente a essa doença.

Foi constatado murchamento de plantas com preseriça de nematóides (Meloidogyne sp.) e de fungo (Sclerotium sp.) Entretanto, na mesma área, pode-se encontrar plantas com nematóides sem sintomas de murchamento e plantas sem nematóides, no início da produção com a possibilidade de haver variabilidade genética, para resistência. A longevidade foi de 8 a 9 meses, uma vez implantada a cuitura e a perda de plantas não foi significativa. No ensaio 2, com adubo orgânico, morreram três plantas de um total de 58 , depois de dois meses de produção.

\section{VARIABILIDADE GENÉTICA}

Os frutos quase não variam na forma e tamanho em sucessivas gerações, nem em diversas condições, portanto esses caracteres são altamente herdáveis. Sete origens foram cultivadas nas condições descritas na secção de propagação em dois tipos diferentes de solo. $\mathrm{O}$ peso médio dos frutos variou nas diferentes origens entre 64 a $164 \mathrm{~g}$ no solo mais rico, e entre 65 a $112 \mathrm{~g}$ no solo mais pobre (Tabela 3 ). A herdabilidade estimada com esses dados foi de $h^{2}=0,89$. Esta estimativa, embora baseada em poucos dados é confirmada por outras observa. ções feitas. A espessura da polpa, não variou nos dois solos. A grossura da polpa varia em função do tamanho. Para fins de ilustração, a forma e tamanho dos frutos foram divididos em cinco classes diferentes na Tabela 4 (Fig. 1).
Os frutos grandes alongados têm uma menor proporção de suco e portanto mais polpa por unidade de peso.

Outra característica, provavelmente genética e que apresentou variaçōes, foi a presençe e a ausência de antocianina observada quando as mudas já estão com um comprimento no caule de 5 a $7,0 \mathrm{~cm}$ e as folhas de até $10 \mathrm{~cm}$ de comprimento aproximadamente. Posteriormente, a antocianina não é tão visível, como acontece com o tomateiro. Acredita-se que seja uma característica genética, pois foi observada variação entre introduções, porém, não dentro das introduções, todas plantadas nas mesmas condições. Falta observar esta característica em algumas outras introduçōes.

A tabela mostra que a área de maior variabilidade é o oeste da Amazônia, e foi encontrada em Humboldt, onde se supõe que seja a área de origem (Brücher, 1973) .

\section{Possibilidades DE CULTIVo}

Brücher (1973) se baseia nas suas experiências com material coletado no Alto Orinoco e plantado em terras da Universidade Central da Venezuela, para chegar à conclusão de que é impossível cultivar o cubiu em escaia comercial, devida à incidência de nematóides.

Por enquanto, nas duas experiências efetuadas em solo franco arenoso com um total de 149 plantas, a presença constatada do nematóide năo impediu a colheita do cubiu com um rendimento maior que o que foi citado por esse autor. A discrepância deve-se talvez ao fato de que, o cubiu, não foi plantado na área de origem e, portanto, foi mais suscetível.

TABELA 3

Variação do peso médio por gramas dos frutos em dois solos em sete origens

\begin{tabular}{|c|c|c|c|c|c|c|c|}
\hline \multirow{2}{*}{ PARCELA } & \multicolumn{7}{|c|}{$O R \perp G E M$} \\
\hline & 13 & 17 & 18 & 130 & 131 & 413 & 414 \\
\hline SOLO POBRE & 67.0 & 74,6 & 77,7 & 111,9 & 88,1 & 69,2 & 65,0 \\
\hline SOLO RICO & 73,0 & 107,0 & 94,0 & 164,7 & 107,6 & 75,5 & 63,7 \\
\hline
\end{tabular}


TABELA 4

Variaçăo de forma, tamanho e peso do fruto, presen ̧̧a de antocianina nos caules das mudas de acordo com a origem

\begin{tabular}{|c|c|c|c|c|c|c|c|c|c|c|c|c|c|}
\hline & \multicolumn{2}{|c|}{ MEDIDAS (CM) } & & \multicolumn{10}{|c|}{ LOCALIDADES } \\
\hline Classes & $\begin{array}{l}\text { Trans- } \\
\text { versais }\end{array}$ & $\begin{array}{l}\text { Longitu- } \\
\text { dinais }\end{array}$ & $\begin{array}{l}\text { Peso } \\
\text { (g) }\end{array}$ & 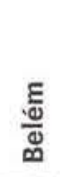 & 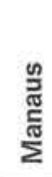 & 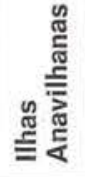 & बूँ & $\stackrel{\varpi}{\oplus}$ & 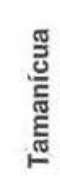 & 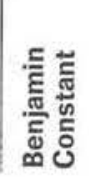 & $\begin{array}{l}\frac{8}{0} \\
\frac{\pi}{\pi} \\
\frac{\pi}{\pi} \\
\frac{\pi}{4} \\
\frac{1}{2}\end{array}$ & 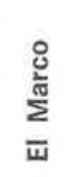 & 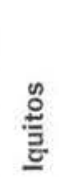 \\
\hline Grande ovalado & $6,0-8,2$ & $9,0-10,0$ & $150-400$ & & & & $\mathrm{x}_{\mathrm{a}}$ & & & & & & $X^{A}$ \\
\hline Grande redondo & $7,0-8,6$ & $6,56,9$ & $150-300$ & & & & & $x$ & $x_{a}$ & & & $X A$ & $x_{A}^{a}$ \\
\hline Mediano ovalado & $5,0-$ & $8,5-10,0$ & $60-145$ & & & & & $x$ & & & & & \\
\hline Mediano redondo & $4,5-6,5$ & $5,0-5,5$ & $60-145$ & $x_{a}^{A}$ & $x$ & $x$ & & & & $\mathrm{x}$ & & & \\
\hline Pequeno redondo & 4,0 & 3,5 & $30-40$ & & & & & & & $x$ & $\mathrm{x}$ & & $x_{a}$ \\
\hline
\end{tabular}

A - Presença de antocianina no caule.

a- Ausência de antocianina no caule.

Os experimentos realizados até o momento não são suficientes para generalizar-se o cultivo puro, e é possível que seja necessário recorrer-se a uma cultura mista, com plantas resistentes aos nematóides ou outras doenças.

A produtividade é provável que possa ser aumentada mediante a seleção das introduções mais resistentes e produtivas. Dez quilos de cubiu produzem, aproximadamente, 3 litros de doce e 1,5 litros de geléia ou 7,5 iitros de suco puro. Portanto, uma plantação com um rendimento de 70 ton/ha, poderá render $21.000 \mathrm{li}$ tros de doce, e 10.500 litros de geléia ou 52.000 litros de suco puro por hectare. Embora as donas de casa possam utilizar o material diretamente, seria desejável a instalação de uma indústria que fabricasse geléia e suco de cubiu ou de outras espécies frutíferas amazonenses, para substituir os importados numa primeira etapa a tentar, posteriormente, introduzí-ios no sul do país e no estrangeiro.

\section{Perspectivas De melhoramento genético}

A variabilidade genética de caracteres altamente herdáveis como o são o tamanho, a forma do fruto $€$ a presença de antocianina no caule, revela que o reservatório de variabilidade para o melhoramento é grande. Os objetivos que foram fixados para o cubiu foram os seguintes :

1 - Resistência aos nematóides, mediante a colheita de sementes das plantas sobreviventes em solos infestadics;

2 - Diminuição do número de sementes para transformar essa energia em suco. Para csse fim, foram tratadias sementes de duas variedades de cubiu com colchicina em três tratamentos diversos, em concentração de $0,5 \%$, de 24 a 8 horas, e concentração de $0,1 \%$ durante oito horas para tentar obter autotetraplói cies. Cs autotetraplóides, produzem habitual mente menos sementes. 
Para localizar os tetraplóides foi tentada a observação dos estomatos, todavia o Setor de Botânica do INPA não conseguiu, devida à alta pilosidade das folhas.

Assim, atuairnente estamos medindo o nú mero de sementes que os frutos de cada planta contêm.

Com esse mesmo fim e para criar variabilidade adicional para resistência aos nematóides, rapidez de crescimento, foi tratada a espécie vinda de Belém com metano sulfanato de etilo (EMS), durante 22 horas a três concentrações de $4 \%$, $6 \%$ 。 e $8 \%$ 。. Nos três tratamentos, as plantas $M_{1}$ germinaram bem com uma demora de um dia com respeito ao controle. Dois meses depois na época do transplante a diferença foi mais visivel.

\section{SUMMARY}

The collection, agronomic behavior and variability of cubiu (Solanum topiro $\mathrm{H} \& \mathrm{~B}$ ), an herbaceous fruit plant, is described.

Thirty five accesions were collected in Amazonia from Belém do Pará (Brazil) till Iquitos (Peru). A large genetic variability was found for shape and size fruit, specially in the west of the region. Part of the collection was planted. The production began six to seven months after sowing and practically finished three months later. It varied per plant from $2.500 \mathrm{~kg}$ ot $14.000 \mathrm{~kg}$ depending on soil conditions and genotype.

\section{BIBLIOGRAFIA CITADA}

BRÜCHER, $\mathrm{H}$.

1968 - Die genetischen Reserven Sudamerikes für die Kulturpflanzen züchtung. Theor and appl. Gentics 38:9-22.

1973 - Plant genetics and development in tropical zones. Applied Sciences and Development, 2:85-95.

CORRÊA, M.P.

1931 - Diccionário das plantas úteis do Brasil e das exóticas cultivadas. Vol. II - Rio de Janeiro.

DUCKE, A.

1946 - Plantas de cultura pré-colombiana na Amazônia brasileira. Notas sobre as espécies ou formas espontâneas que supostamente lhes teriam dado origem. Bol. Tecn. Inst. Agron. Norte, Belém, 8.

KenNARD, W.C, \& Winters, H.F.

1960 - Some fruits and nuts for the tropics. Miscellaneous Publ, n. 801 Agric. Res. Serv. USDA. Nat. Acad. Sci. (USA) 1975. Underexploited tropical plants with promising value. Advisory studies and special reports. $\mathrm{N} \circ 16$.

PAtı̃ก๊o, V.M.

1962 - Edible fruits of Solanum in South America: historic and geographic references. Bot. Museum Leaflets. Harvard University, Camb. Mass. 19(10):215-234

SChUltes, R.E. \& ROMERo-CASTAñEedA, R.

1962 - Edible fruits of Solanum in Colombia. Bot. Museum Leaflets. Harvard Univer. sity, Camb. Mass. 19(10):235-286.

SENDTNER, O.

1846 - En Martius, “Flora Brasuliensis” pt. 6. 